\title{
EFEKTIVITAS MODEL PEMBELAJARAN PROBLEM BASED LEARNING TERHADAP HASIL BELAJAR IPA DITINJAU DARI KEMAMPUAN BERKOMUNIKASI SISWA
}

\section{EFFECTIVITY OF LEARNING MODEL PROBLEM BASED LEARNING TOWARD SCIENCE LEARNING OUTCOMES OBSERVED FROM STUDENTS' COMMUNICATION SKILL}

\author{
Nestri Indah Wulandari ${ }^{1}$, Astuti Wijayanti ${ }^{1 *}$, Widodo Budhi ${ }^{2}$ \\ ${ }^{1}$ Program Studi Pendidikan IPA, Fakultas FKIP Universitas Sarjanawiyata Tamansiswa Yogyakarta, Indonesia \\ ${ }^{2}$ Program Studi Pendidikan Fisika Fakultas FKIP Universitas Sarjanawiyata Tamansiswa Yogyakarta, Indonesia \\ *Email: astuti.wijayanti@ustjogja.ac.id
}

Diterima: 3 Januari 2018. Disetujui: 28 Maret 2018. Dipublikasikan: 31 Maret 2018

\begin{abstract}
Abstrak: Penelitian ini bertujuan untuk mengetahui perbedaan hasil belajar IPA antara pembelajaran menggunakan model Problem Based Learning dengan pembelajaran langsung ditinjau dari kemampuan berkomunikasi siswa. Jenis penelitian ini adalah kuasi ekperimen. Penelitian ini dilakukan di SMP Negeri 11 Yogyakarta tahun ajaran 2016/2017. Hasil penelitian menunjukkan bahwa hasil belajar IPA yang menggunakan model Problem Based Learning memperoleh skor rerata 21,22 dan pembelajaran langsung memperoleh skor rerata 18,09. Kemampuan berkomunikasi yang pembelajarannya menggunakan Problem Based Learning memperoleh skor rerata 96,00 dan pembelajaran langsung termasuk memperoleh skor rerata 90,00. Sehingga dapat dinyatakan ada perbedaan yang signifikan. Kesimpulannya, ada signifikan, sehingga ada perbedaan hasil belajar Ipa siswa kelas VII SMP Negeri 11 Yogyakarta tahun ajaran 2016/2017 antara pembelajaran menggunakan Problem Based Learning dengan pembelajaran langsung ditinjau dari kemampuan berkomunikasi siswa.
\end{abstract}

Kata Kunci : Hasil belajar IPA, Problem Based Learning, Kemampuan Berkomunikasi

\begin{abstract}
The objective of this study is to know the difference of science learning outcomes between learning using Problem Based Learning model and direct learning observed from students' communication skill. This research is quasi-experiment. This study was conducted at the Junior High School 11 Yogyakarta in the academic year of 2016/2017. The study showed that the average score of science learning outcomes which uses Problem Based Learning model was 21.22, whereas direct learning got the average score of 18.09. Communication skill that the learning process uses Problem Based Learning got the average score of 96.00 whereas direct learning got the average score of 90.00 . In conclusion, there is significance, so there is the difference of science learning outcomes of students of class VII of SMP Negeri 11 Yogyakarta academic year 2016/2017 between learning using Problem Based Learning with direct learning in terms of students' communication ability.
\end{abstract}

Keywords : Science learning outcomes, Problem Based Learning, Communication Skill

\section{PENDAHULUAN}

Belajar merupakan kegiatan yang kompleks yang membuat siswa dapat menjadi generasi kreatif yang dapat menyelesaikan permasalahan yang terjadi di lingkungan sekitar. Pembelajaran IPA mengembangkan pemahaman tentang berbagai macam gejala alam, konsep, prinsip IPA yang bermanfaat dan dapat diterapkan dalam kehidupan sehari-hari. Kegiatan pembelajaran yang efektif sangat dibutuhkan siswa untuk membantu mengembangkan daya pikir siswa dengan tanpa mengesampingkan tingkat pemahaman siswa sesuai dengan usia perkembangannya. Berdasarkan KTSP 2006 tujuan dari pembelajaran IPA adalah agar siswa memiliki kemampuan untuk mengembangkan pengetahuan yang dimilikinya dan dikaitkan dengan konsep-konsep IPA yang diperoleh pada saat mengikuti proses belajar dan dapat diterapkan dalam kehidupan [1]. Proses pembelajaran IPA menekankan pada pemberian pengalaman langsung untuk mengembangkan kompetensi agar menjelajahi dan memahami alam sekitar secara ilmiah.

Berdasarkan hasil observasi yang dilakukan di SMP Negeri 11 Yogyakarta, pada saat pembelajaran IPA nampak terdapat sebagian siswa yang tidak memperhatikan materi yang disampaikan guru. Sebagian besar siswa berbicara dengan teman sebangku. Siswa terlihat jarang bertanya dan mengembangkan keterampilan pemecahan masalah. Dalam proses pembelajaran guru cenderung lebih banyak memberikan penjelasan materi atau guru sebagai sumber utama pengetahuan dengan menggunakan power point dalam proses pembelajaran. Hal tersebut membuat siswa jenuh, bosan dan ramai saat proses pembelajaran berlangsung. Hal tersebut mengakibatkan siswa kurang terlatih berpikir kritis dalam menemukan konsep materi secara inquiri. 
Berdasarkan uraian tersebut menunjukkan bahwa kemampuan berkomunikasi siswa masih rendah dalam pembelajaran IPA, sehingga memerlukan adanya dorongan untuk menghasilkan komunikasi yang efektif. Komunikasi tidak hanya dilakukan secara personal namun juga dilakukan dengan kelompok dan komunikasi massa [6]. Keterampilan komunikasi digunakan dalam pembelajaran untuk menyampaikan hasil kajian ilmiah, baik secara langsung maupun tidak langsung, baik secara pribadi maupun kelompok.

Kemampuan berkomunikasi siswa yang menurun menyebabkan hasil belajar siswa menjadi rendah. Untuk mengatasi hal tersebut perlu adanya pemilihan model pembelajaran yang efektif digunakan yaitu model pembelajaran Problem Based Learning. Problem Based Learning merupakan salah satu model pembelajaran yang menuntut aktivitas mental siswa untuk memahami suatu konsep melalui situasi dan masalah yang disajikan pada awal pembelajaran dengan tujuan untuk melatih siswa menyelesaikan masalah [3]. Model pembelajaran $P B L$ membuat aktivitas diskusi lebih menarik dari diskusi biasanya, sehingga aktivitas siswa dikatakan aktif saat siswa telah melaksanakan fase-fase dalam kegiatan pembelajaran [4]. Problem Based Learning siswa belajar dalam kelompok untuk memahami persoalan yang dihadapi . Dalam pembelajaran menggunakan $P B L$ siswa dapat secara aktif terlibat dalam pembelajaran yang dilakukan sehingga pembelajaran menjadi bermakna. Penyedian kesempatan belajar sendiri dan beraktivitas seluasluasnya diharapkan dapat membantu siswa dalam memahami konsep yang dipelajari [2-5].

Langkah-langkah $P B L$ yang digunakan dalam pemecahan masalah yaitu mengidentifikasi masalah, menentukan masalah, Brainstorming, menentukan tujuan pembelajaran, memilih solusi penyelesaian masalah, belajar mandiri dan setiap anggota kelompok menjelaskan hasil belajar mandiri [5]. Dalam pembelajaran, digunakan LKS untuk memunculkan permasalahan dan menangani masalah sesuai dengan langkah-langkah $P B L$. LKS dapat membantu siswa bekerja secara berkelompok dan mendiskusikan permasalahan yang terdapat di dalam LKS serta mengkomunikasikan hasil diskusi.

Berdasarkan uraian tersebut, maka penelitian ini bertujuan mempelajari ada perbedaan hasil belajar IPA siswa kelas VII SMP Negeri 11 Yogyakarta tahun ajaran 2016/2017 antara pembelajaran menggunakan model pembelajaran Problem Based Learning dengan pembelajaran langsung ditinjau dari kemampuan berkomunikasi siswa.

\section{METODE PENELITIAN}

Penelitian ini dilakukan di SMP Negeri 11 Yogyakarta yang berlokasi di Jl. HOS Cokroaminoto 127 Yogyakarta pada semester genap tahun ajaran
2016/2017. Jenis penelitian ini adalah Quasi Exsperiment. Terdapat 3 variabel dalam penelitian ini yaitu variabel bebas, variabel terikat dan variabel kontrol. Variabel bebas dalam penelitian ini adalah model pembelajaran Problem Based Learning dan model pembelajaran langsung, variabel terikat dalam penelitian ini adalah hasil belajar IPA, dan variabel kontrol dalam penelitian ini adalah kemampuan berkomunikasi siswa. Desain penelitian ini untuk mengetahui perbedaan hasil belajar siswa yang pembelajarannya menggunakan model pembelajaran Problem Based Learning dan model pembelajaran langsung. Rancangan desain dalam penelitian ini menggunakan hasil data pretest dan posttest. Data Pretest digunakan sebagai data sebelum perlakuan dan untuk mengetahui kedua kelompok yang akan diteliti berasal dari kemampuan yang sama. Data posttest adalah hasil data penelitian berupa deskriptif dan komparatif.

Populasi dalam penelitian ini adalah semua siswa kelas VII SMP Negeri 11 Yogyakarta sebanyak 135 siswa yang terdiri dari 4 kelas yaitu kelas VII A (34 siswa), VII B (35 siswa), VII C (34 siswa) dan VII D (32 siswa). Sampel dalam penelitian ini diambil menggunakan teknik random sampling, yaitu dari 4 kelas yang ada diambil 2 kelas secara acak dan terpilih kelas VII A dan VII D. Kelas VII D sebagai kelas eksperimen dan kelas VII A sebagai kelas kontrol.

Teknik pengumpulan data yang digunakan dalam penelitian ini adalah teknik tes, angket dan dokumentasi. Teknik tes digunakan untuk mengumpulkan nilai hasil belajar IPA. Teknik angket digunakan untuk mengumpulkan data kemampuan berkomunikasi siswa. Teknik dokumentasi digunakan untuk memperoleh daftar nama siswa. Instrumen penelitian yang digunakan meliputi tes hasil belajar dan angket untuk kemampuan berkomunikasi siswa. Analisis data yang digunakan dalam penelitian ini yaitu analisis deskriptif dan analisis komparatif menggunakan uji anakova.

\section{HASIL DAN PEMBAHASAN}

Tes hasil belajar IPA yang digunakan dalam penelitian ini terdiri dari 30 butir soal, dengan 27 butir soal valid dan 3 butir soal gugur. Setiap jawaban yang benar diberi skor 1 dan jawaban salah diberi skor 0. Hasil belajar IPA dari kedua kelompok didapat skor maksimal ideal 27 dan skor minimun ideal 0. Dengan memperhatikan nilai rata-rata ideal dan simpangan baku ideal, maka diperoleh kurva normal ideal (Tabel 1).

Tabel 1. Kriteria kurva normal ideal

\begin{tabular}{cc}
\hline Interval & Kategori \\
\hline $20,2635 \leq \bar{X} \leq 27$ & Sangat Tinggi \\
\hline
\end{tabular}




\begin{tabular}{cc}
\hline $15,7545 \leq \bar{X}<20,2635$ & Tinggi \\
$11,2455 \leq \bar{X}<15,7545$ & Sedang \\
$6,7365 \leq \bar{X}<11,2455$ & Rendah \\
$0,000 \quad \leq \bar{X}<6,7365$ & Sangat Rendah \\
\hline
\end{tabular}

Tabel 2. Kriteria kurva normal

\begin{tabular}{cc}
\hline Kriteria Kurva Normal & Kriteria \\
\hline $104,052 \leq \overline{\mathrm{X}} \leq 130,000$ & Sangat Tinggi \\
$86,684 \leq \overline{\mathrm{X}}<104,052$ & Tinggi \\
$69,316 \leq \overline{\mathrm{X}}<86,684$ & Sedang \\
$51,948 \leq \overline{\mathrm{X}}<69,316$ & Rendah \\
$26 \overline{\mathrm{X}}<51,948$ & Sangat Rendah \\
\hline
\end{tabular}

Deskripsi data hasil belajar IPA yang pembelajarannya menggunakan model pembelajaran Problem Based Learning diperoleh skor tertinggi= 27,00 , skor terendah $=12,00$, rerata $=21,22$ dan simpangan baku $=4,33$. Rerata hasil belajar IPA yang menggunakan Problem Based Learning 21,22. Kelompok ini berada pada interval $20,2635 \leq \mathrm{X}^{-} \leq$ 27,00 termasuk dalam kategori sangat tinggi. Sedangkan rerata hasil belajar IPA yang menggunakan model pembelajaran langsung yaitu 18,09 . Kelompok ini berada pada interval $15,7545 \leq$ $\mathrm{X}^{-}<20,2635$, dapat disimpulkan bahwa hasil belajarnya termasuk dalam kategori tinggi.

Angket kemampuan berkomunikasi siswa yang digunakan dalam penelitian ini terdiri dari 30 butir pertanyaan, dengan 26 butir pertanyaan valid dan 4 butir pertanyaan gugur. Diperoleh skor maksimum ideal sebesar 130 dan skor minimal ideal 26. Dengan memperhatikan nilai rata-rata ideal dan simpangan baku ideal, maka diperoleh kurva normal ideal seperti Tabel 2.

Deskripsi data kemampuan berkomunikasi yang pembelajarannya menggunakan model Problem Based Learning diperoleh skor tertinggi $=117$, skor terendah $=79$, simpangan baku $=9,38$ dan rata-rata $=$ 96,00 . Kemampuan berkomunikasi dengan skor ratarata 96,00 jika dibandingkan dengan kurva kriteria kurva normal, kelompok ini berada pada interval $86,684 \leq \mathrm{X}^{-}<104,052$ termasuk kategori tinggi. Sedangkan deskripsi data kemampuan berkomunikasi yang pembelajarannya menggunakan model pembelajaran langsung diperoleh skor tertinggi $=115$, skor terendah $=72$, simpangan baku $=11,88$ dan ratarata $=90,00$. Rerata skor sebesar 90,00 jika dibandingkan dengan kriteria 86,684 $\leq \mathrm{X}^{-}<104,052$ termasuk kriteria tinggi.
Analisis hipotesis yang digunakan dalam penelitian ini adalah analisis uji anakova. Terdapat tiga persyaratan yang harus dipenuhi dalam melakukan uji anakova. Persyaratan yang dimaksud adalah data harus berdistribusi normal, varian antar kelompok harus homogen, dan distribusi data linier. Untuk mengetahui normal atau tidaknya suatu sebaran menggunakan nilai probabiliti (p). Taraf signifikan yang digunakan 5\% sehingga apabila diperoleh nilai $\mathrm{p}>0,05$ maka data penelitian ini berdistribusi normal. Berdasarkan hasil uji normalitas (Tabel 3) diperoleh nilai probabiliti dari masing-masing variabel lebih besar dari 0,05 sehingga dapat disimpulkan bahwa semua data berdistribusi normal. Untuk mengetahui homogen atau tidaknya menggunakan nilai probabiliti. Jika diperoleh $\mathrm{p}>0,05$ maka varian homogen. Berdasarkan data hasil uji homogenitas (Tabel 4) diperoleh $\mathrm{p}>$ dari 0,05 maka dapat disimpulkan varian kedua kelompok adalah homogen. Untuk mengetahui status linier tidaknya menggunakan nilai probabiliti. Jika $\mathrm{p} \geq 0,05$ maka bersifat Linier.

Berdasarkan Tabel 5 diperoleh hasil Fhitung sebesar 0,346 dengan $\mathrm{p}=0,566$ dari hasil tersebut diketahui bahwa $p \geq 0,05$. Karena $p \geq 0,05$ maka hubungan antara kemampuan berkomunikasi siswa dan hasil belajar IPA bersifat linier. Berdasarkan Tabel 6 diperoleh Fhitung $=4,238$ dengan $\mathrm{p}=0,041$ oleh karena $\mathrm{p} \leq 0,05$ maka hipotesis dapat diterima dan dapat disimpulkan bahwa ada perbedaan yang signifikan antara hasil belajar IPA yang pembelajarannya menggunakan model pembelajaran Problem Based Learning dengan model pembelajaran langsung ditinjau dari kemampuan berkomunikasi siswa.

Kecenderungan hasil belajar IPA yang pembelajarannya menggunakan model pembelajaran Problem Based Learning termasuk kategori sangat tinggi yaitu berada interval $20,2635 \leq X^{-} \leq 27,00$. Hal ini sesuai dengan pendapat Trianto bahwa pembelajaran berdasarkan masalah menyajikan situsi masalah yang otentik dan bermakna kepada siswa sehingga dapat memberikan kemudahan kepada mereka untuk melakukan penyelidikan dan inkuiri [12]. Menurut Lhistya Dewi. et al penerapan model $P B L$ membuat siswa lebih mudah dalam memecahkan masalah, siswa merancang kegiatan belajaranya sendiri sesuai dengan masalah yang diberikan untuk dikerjakan secara berkelompok agar menemukan solusi dari permasalahan tersebut [7]. Model pembelajaran Problem Based Learning menekankan siswa untuk berusaha menyelesaikan masalah berdasarkan pengetahuan yang telah mereka miliki sebelumnya dan menghubungkan antara materi terdahulu dengan materi baru yang dipelajari.

Kecenderungan hasil belajar IPA pada model pembelajaran langsung termasuk kategori tinggi yaitu berada pada interval $15,7545 \leq \mathrm{X}^{-}<$ 20,2635. Hal ini sesuai dengan pendapat Abdul 
Majid bahwa siswa hanya memiliki sedikit kesempatan untuk terlibat secara aktif, sulit bagi siswa untuk mengembangkan keterampilan sosial dan interpersonal [1]. Sedangkan menurut Lisa Ariyanti Pohan selama proses pembelajaran hampir tidak ada pertanyaan dari siswa dan jika guru melontarkan pertanyaan kepada siswa pada saat proses pembelajaran di kelas sedang berlangsung, jawaban yang diberikan siswa seringkali tidak sesuai dengan yang diharapkan oleh guru [9]. Pada model ini pembelajaran hanya berpusat pada guru dengan pembelajaran satu arah, sehingga membuat siswa tidak bersemangat dalam pembelajaran dan membuat hasil belajar IPA siswa menjadi rendah.

Tabel 3. Hasil uji normalitas sebaran

$\begin{array}{llll}\text { Variabel } & d b & X^{2} & p\end{array}$

\begin{tabular}{lcccc}
\hline & \multicolumn{5}{c}{ hitung } & & \\
\hline PBL & 9 & 7,80 & 0,55 & Normal \\
$\begin{array}{l}\text { Kemampuan } \\
\text { berkomunikasi }\end{array}$ & 9 & 4,61 & 0,86 & Normal \\
$\begin{array}{l}\text { Pembelajaran } \\
\text { langsung }\end{array}$ & 9 & 10,51 & 0,31 & Normal \\
$\begin{array}{l}\text { Kemampuan } \\
\text { berkomunikasi }\end{array}$ & 9 & 3,84 & 0,92 & Normal \\
\hline
\end{tabular}

Tabel 4. Hasil uji homogenitas

\begin{tabular}{llcl}
\hline \multicolumn{1}{c}{ Variabel } & $F_{\text {hitung }}$ & $P$ & \\
\hline $\begin{array}{l}\text { Hasil belajar PBL } \\
\text { dan Langsung }\end{array}$ & 1,307 & 0,228 & Homogen \\
$\begin{array}{l}\text { Kemampuan } \\
\text { berkomunikasi siswa }\end{array}$ & 1,603 & 0,093 & Homogen \\
\begin{tabular}{l} 
PBL dan Langsung \\
\hline
\end{tabular} & & & \\
\hline
\end{tabular}

Tabel 5. Data hasil uji linieritas

\begin{tabular}{lccc}
\hline \multicolumn{1}{c}{ Variabel } & $F_{\text {hitung }}$ & $P$ & Keterangan \\
\hline $\begin{array}{l}\text { Problem Based Learning dan } \\
\text { pembelajaran langsung ditinjau dari } \\
\text { kemampuan berkomunikasi siswa }\end{array}$ & 0,346 & 0,566 & Linier \\
\hline
\end{tabular}

Tabel 6. Data hasil uji Anacova

\begin{tabular}{lllllll}
\hline \multicolumn{1}{c}{ Kelompok } & $J K$ & $d b$ & $R K$ & $F_{\text {hitung }}$ & $p$ & Keterangan \\
\hline Model pembelajaran & & & & & & \\
$\begin{array}{l}\text { Problem Based Learning } \\
\text { dan Model Pembelajaran }\end{array}$ & & & & & & \\
Langsung Ditinjau dari & 85,468 & 1 & 85,468 & 4,238 & 0,041 & Signifikan \\
Kemampuan & & & & & & \\
Berkomunikasi siswa & & & & & & \\
\hline
\end{tabular}

Kecenderungan kemampuan berkomunikasi siswa pada model pembelajaran Problem Based Learning termasuk dalam kategori tinggi yaitu berada pada interval $86,684 \leq \mathrm{X}^{-}<104,052$. Hal ini sejalan dengan pendapat Bekti Wulandari dan Herman Dwi Surjono model Problem Based Learning lebih menekankan pada pertukaran pendapat dan berbagai pengalaman dalam pemecahan masalah [3]. Menurut Maaruf Fauzan. et al penggunaan model Problem Based Learning memberikan kesempatan siswa untuk mengembangkan kemampuan psikomotornya yang berkaitan dengan keterampilan berkomunikasi, representasi, pemodelan dan penalaran [10]. Pada penerapan pembelajaran dengan model pembelajaran Problem Based Learning terjadi komunikasi aktif antara guru dengan siswa, siswa dengan siswa dalam berdiskusi dan bertukar pendapat serta mengkomunikasikan hasil dari diskusi.

Kecenderungan kemampuan berkomunikasi siswa yang pembelajarannya menggunakan model pembelajaran langsung berada pada kategori tinggi yaitu berada pada interval $86,684 \leq \mathrm{X}^{-}<104,052$.
Hal tersebut sejalan dengan pendapat Abdul Majid model pembelajaran langsung bergantung pada gaya komunikasi guru, komunikator yang buruk cenderung menghasilkan pembelajaran yang buruk dan model pembelajaran langsung membatasi kesempatan guru untuk menampilkan banyak perilaku komunikasi positif [1]. Kamaruzzaman menambahkan yaitu gejala-gejala kurangnya komunikasi seperti kurang mampu dalam berbicara, sulit membuka komunikasi dengan orang lain, kurang menjadi pendengar yang baik, kurang memiliki kepedulian terhadap apa yang dikerjakan oleh teman-temannya dan rendah sikap empati terhadap orang lain [6]. Pada proses pembelajaran langsung guru mendominasi pembelajaran sehingga menyebabkan siswa tidak dapat berperan aktif untuk mengkomunikasikan pendapat atau bertanya mengenai materi pembelajaran

\section{KESIMPULAN}

Kecenderungan hasil belajar IPA siswa kelas VII SMP Negeri 11 Yogyakarta tahun ajaran 2016/2017 yang pembelajarannya menggunakan 
model pembelajaran Problem Based Learning termasuk kriteria sangat tinggi dan yang pembelajarannya menggunakan model pembelajaran langsung termasuk kategori tinggi.

Kecenderungan kemampuan berkomunikasi siswa kelas VII SMP Negeri 11 Yogyakarta tahun ajaran 2016/2017 yang pembelajarannya menggunakan model pembelajaran Problem Based Learnig termasuk kriteria tinggi dan yang pembelajarannya menggunakan model pembelajaran langsung termasuk kategori tinggi.

Dari hasil perhitungan dengan menggunakan uji anacova diperoleh $F_{\text {hitung }}=4,238$ dengan $\mathrm{p}=0,041$ oleh karena $\mathrm{p} \leq 0,05$ maka hipotesis dapat diterima. Dengan demikian dapat disimpulkan bahwa ada perbedaan yang signifikan hasil belajar IPA siswa kelas VII SMP Negeri 11 Yogyakarta tahun ajaran 2016/2017 antara pembelajaran yang menggunakan model pembelajaran Problem Based Learning dengan model pembelajaran langsung ditinjau dari kemampuan berkomunikasi siswa.

Rerata skor hasil belajar IPA dan kemampuan berkomunikasi siswa yang pembelajarannya menggunakan model pembelajaran Problem Based Learnig lebih tinggi daripada model pembelajaran langsung. Jadi model pembelajaran Problem Based Learnig lebih efektif dibandingkan dengan model pembelajaran langsung ditinjau dari kemampuan berkomunikasi siswa.

\section{DAFTAR PUSTAKA}

1. Wijayanti, A. (2016). Implementasi model pembelajaran kooperatif tipe tgt sebagai upaya meningkatkan pemahaman konsep fisika dasar mahasiswa pendidikan IPA. Jurnal Pijar Mipa, 11(1).

2. Al-idrus, S. Q. M. J., Hikmawati, H., \& Wahyudi, W. (2015). Pengaruh model pembelajaran berbasis masalah berbantuan video kartun terhadap hasil belajar fisika siswa kelas xi sman 1 sikur tahun ajaran 2014/2015. Jurnal Pijar MIPA, 10(1).

3. Susilawati, S., Jamaluddin, J., \& Bachtiar, I. (2017). Pengaruh Model Pembelajaran Berbasis Masalah (Pbm) Berbantuan Multimedia Terhadap Kemampuan Berpikir Kritis Peserta Didik Kelas Vii SMP Negeri 2 Mataram Ditinjau Dari Kemampuan Akademik. Jurnal Pijar Mipa, 12(2).

4. Bekti Wulandari dan Herman Dwi Surjono. 2013. Pengaruh Problem Based Learning Terhadap Hasil Belajar Ditinjau Dari Motivasi Belajar PIC di SMK. Jurnal Pendidikan Vokasi. 3 (2), 178-191

5. Suryani, I. (2015). Efektivitas Model Pembelajaran Problem Based Learning (PBL) Terhadap Hasil Belajar Biologi Siswa Pada
Materi Pencemaran Lingkungan Di Kelas X SMA Negeri 2 Polewali. bionature, 16(2).

6. Susanti, A., \& Wijayanti, A. (2017). Think Pair Share: Hasil Belajar IPA dan Kerjasama Siswa. Jurnal Pijar Mipa, 12(2).

7. Kamaruzzaman. 2016. Analisis Keterampilan Komunikasi Interpersonal Siswa. Jurnal Konseling. 2 (2), 202-210

8. Dewi, N. L. K. L., Suwatra, I. I. W., \& Rati, N. W. (2014). Pengaruh Model PBL (Problem Based Learning) Terhadap Hasil Belajar IPA Siswa Kelas V Tahun Pelajaran 2013/2014 Di SD Segugus 1 Kecamatan Marga Kabupaten Tabanan. MIMBAR PGSD Undiksha, 2(1).

9. Fathonah, N., Ibnu, S., \& Suharti, S. (2016). Pengaruh Pembelajaran Berbasis Pemecahan Masalah Berbantuan Jurnal Belajar Terhadap Kemampuan Metakognitif. Jurnal Pijar Mipa, 11(1).

10. Wuryastuti, S. (2008). Inovasi pembelajaran IPA di sekolah dasar. Jurnal Pendidikan Dasar, 9, 13-19.

11. Maaruf Fauzan. Et al. 2017. Penerapan Model Problem Based Learning pada Pembelajaran Materi Sistem Tata Surya Untuk Meningkatkan Haisl Belajar Siswa. Jurnal Pendidikan Sains Indonesia, 5(1), 27-35.

12. Utomo, T., Wahyuni, D., \& Hariyadi, S. (2014). Pengaruh Model Pembelajaran Berbasis Masalah (Problem Based Learning) Terhadap Pemahaman Konsep dan Kemampuan Berpikir Kreatif Siswa (Siswa Kelas VIII Semester Gasal SMPN 1 Sumbermalang Kabupaten Situbondo Tahun Ajaran 2012/2013). Jurnal Edukasi, 1(1), 5-9.

13. Trianto. 2007. Model-Model Pembelajaran Inovatif Berorientasi Konstruktivis. Jakarta : Prestasi Pustaka.

14. Nafiah, Y. N., \& Suyanto, W. (2014). Penerapan Model Problem-Based Learning untuk Meningkatkan Keterampilan Berpikir Kritis dan Hasil Belajar Siswa. Jurnal Pendidikan Vokasi, 4(1). 